\title{
Analyzing The Critical Factors for Humanitarian Response on Flood-Related Disaster
}

\author{
${ }^{1}$ Faculty of Industrial Management, Universiti Malaysia Pahang, 26600 Pahang, Malaysia. \\ 2ESB Business School, Reutlingen University, Germany. \\ ${ }^{3}$ College of Business Management and Accounting, Universiti Tenaga Nasional, 26700 Pahang, Malaysia. \\ 4 UMP Technology Sdn Bhd, Pahang, Malaysia
}

Puteri Fadzline Muhamad Tamyez ${ }^{1}$, Natalie Christiane Isabella Gerth², Abdul Rahman Zahari3 ${ }^{3}$, Mohd Nizam Abdul Rashid4

ABSTRACT - Every year, thousands of people in Malaysia have to be moved out and be relinquished from their homes due to heavy rainfall and poor irrigation system that led to flood situation especially on monsoon season. Thus, the current study aims to concentrate on the two central aspects of disaster management in the context of flood disaster management in Kuantan, Pahang by the means of a mixed-method approach. The effectiveness of communication mechanisms in the case of floods is assessed with quantitative analysis using descriptive design. On another note, this study also takes a closer look at the underlying logistical framework found in flood disaster contexts and identifies its critical success factors via a qualitative research technique. Using thematic analysis, in-depth semi-structured interviews are analysed to arrive at conclusions regarding the critical success factors. Findings on the effectiveness of disaster communication indicated that the communication between authorities, agencies, non-government organizations and flood victims are still in need of improvement particularly related to emergency updates and increasing community awareness on the right actions for upcoming floods. The study also proved that coordination, communication, knowledge, and preparedness are the critical success factors for humanitarian response in the case of flood management. It is vital to protect the communities from flood disaster; hence, a clear and precise standard operating procedure need to be in place and must be integrated among all related agencies which will benefits the stakeholders.
ARTICLE HISTORY

Received: $23-12-2020$

Revised: 11-2-2021

Accepted: 1-3-2021

\section{KEYWORDS}

Flood,

Flood disaster management,

Disaster communication,

Humanitarian logistics

\section{INTRODUCTION}

In Malaysia, flash floods have caused a small affect especially in densely populated and urbanized areas. Conversely, the scenarios are different in the state of Pahang which the affected areas are usually rural areas and floods cover vast stretches of land. Therefore, the damage suffered can still be high even though the value of properties is lower (Zakaria et al, 2017). The steady growth of industries in Pahang likes transportation and petrochemical sectors have led to a comparably rapid growth of urbanization (Shakir et al, 2015) This urban development with building of roads and buildings consequently led to fewer stretches of land covered by vegetation, which is an important factor causing rapid river flow (Chan, 1997 ; Gupta, 2010). For instance, during the most recent monsoon at the beginning of 2018, 9,000 residents had to be evacuated in the state of Pahang alone (Malay Mail Online, 2018). Looking at the history of Kuantan with floods, its location in the Kuantan River Basin and its low laying nature are important factors (Zaidi, Akbari, \& Ishak, 2014). During the North-East monsoon season, massive precipitation between November and March is to be expected in the area. The Kuantan River starts from Sungai Lembing, passing through Kuantan City and is then drained into the South China Sea, covering an area of $1630 \mathrm{~km}^{2}$ (Shakir et al, 2015 ; Zaidi, Akbari, \& Ishak, 2014). Due to the tropical climate, torrential rains have regularly led to spilling over of the river surface in the past decades. Runoffs also inundate low laying areas, affecting always the social and economic life of the societies residing there.

In 2001, three decades after the latest large-scale flood incident in Pahang, floods as a result from over spilling rivers affected 18,000 residents and 22,940 $\mathrm{km}^{2}$ of land (Zaidi, Akbari, \& Ishak, 2014). Another floods situation of 2011/2012 affected nearly 6,000 residents in Kuantan after continuous rainfall caused sudden flooding of residential areas. Roads and vehicles were left in bad condition, reportedly due to the lacking drainage system in place during that time (Zaidi, Akbari, \& Ishak, 2014). The worst flood to date, however was experienced by Pahang in 2013, following heavy rainfall and the shift in land-use that took place around that time (Zaidi, Akbari, \& Ishak, 2014). Kuantan in particular, with its low laying nature was in severe distress: more citizens than in the previous years had to evacuate their homes and the city suffered major damages to roads, buildings and other structures (Jamaludin, Jaafar, \& Abdullah, 2013). Throughout the state of Pahang, where approximately 38,000 Malaysians in Pahang were evacuated from their homes to shelters. 32,000 of these evacuees sought refuge at the shelters set up in Kuantan (Malay Mail, 2013).

Department of Irrigation and Drainage (DID) has projected the vulnerable are to flood disaster in Malaysia is 9 percent of the country's total area or equivalent to $29,800 \mathrm{~km}^{2}$. Importantly, this will affect 4.82 million people or close to 21 percent of the country's total population. Statistics show that the losses and damages per year accumulate to approximately 
RM 915 million (Department of Irrigation and Drainage, Ministry of Environment and Water, 2020). In addition, Malaysia's previous largest flooding event happened in December 2014 which affected more than 230,000 individuals (Emergency Events Database (EM-DAT), 2017). The fact is that floods are unavoidable and occur annually. Future cases of flooding in the region will be even more monumental in nature, both in terms of dimension and impact (Chan, 2012). A reconsideration of the current strategy is therefore essential to improve the preparedness, mitigation, response and recovery for Malaysia and its citizens in the face of natural disaster. Current literature identifies several critical areas related to the management of natural disasters and in particular flood events (Chan, 2012; Khalid, \& Shafiai, 2015; Saifulsyahira et al., 2016; Shafiai, 2016). Due to the dispersed nature of flood management in Malaysia, lack of coordination is considered as a bold issue (Saifulsyahira et al., 2016). Apart from that, a large number of government agencies and other organisations involved in evacuation and aid distribution contributes to this coordination issue (Shafiai, 2016). Moreover, the approach taken towards disaster and flood management in Malaysia as off now is still a highly reactive one and not one that is centred around proactive action (Chan, 2012; Khalid, \& Shafiai, 2015). The government agency in charge of coordinating flood management, the engineering based DID, focuses on structural measures and not on non-structural, interdisciplinary solutions (Chan, 2012).

The motif of this study is focused at cultivating the situation for the Pahang local people and offering solutions and ideas for a prevailing and pressing issue. Thus, the specific objectives of this research are; (i) to measure the satisfaction of the communication mechanism among flood victims, and (ii) to determine the critical success factors in managing humanitarian logistics in the case of flood events. The reminder of the study is structured as follows: Section 2 provides a review of the relevant literature and then details of research method applied are presented in Section 3, while Section 4 explains the results and discussion, followed by a short conclusion and implications for the study in Section 5 .

\section{LITERATURE REVIEW}

\section{Disaster Communication}

Disaster communication can be classified under crisis and risk emergency communication (CERC) and describes what takes place once an event has taken place, in its immediate aftermath, and sometimes as preventive action when it is about to happen (Manuel, 2014). Figure 1 displays the CERC lifecycle that was adapted from the Centre of Disease Control and Prevention (CDC), of the U.S. Department of Health and Human Services. The CERC lifecycle is a tool utilised to break down the different stages of a disaster event in regard to the communication that relates to it (Centre of Disease Control and Prevention, 2014). Taking the disaster event into the pictured phases provides assistance to those responsible for communicating with the public, media, other agencies and organisations. It helps anticipate the information needs that will arise, identifying both the source as well as the time frame of its appearance. Each phase requires specific information (Centre of Disease Control and Prevention, 2014; Reynolds \& Shenhar, 2009). The pre-crisis phase takes on the task of preparing the general public for potential disaster events and similarly provides information to educate the public about the risks. In the initial phase, it is important to recognize that communication should reduce any uncertainties and help the public understand the various organisations involved in handling the disaster, including the specific responsibilities each has. Most importantly, in this phase official communication channels and methods should be established for future interaction between the information providing organisation and the public (Centre of Disease Control and Prevention, 2014).

While the initial phase is centred around rapid initial communication, the maintenance phase seeks to keep the general public updated about current developments, ongoing risks and possible tools for mitigation, and also to correct any circulating information that is incorrect or unclear (Centre of Disease Control and Prevention, 2014) and to prevent issues with mixed messages provided to the public (Parmer et al., 2016) Following the immediate disaster events, during the resolution phase in the CER lifecycle communication should be centred on providing information about the ongoing reconstruction and rebuilding activities to keep the communities informed. At the same time, this leaves room for the promotion of risk mitigation and risk avoidance tools, and personal preparedness for residents (Centre of Disease Control and Prevention, 2014). The last phase of the communication lifecycle is referring to evaluation that serves as a time stretch during which lessons learned can be collected, categorised and documented for future reference. The lessons learned can be used as a basis for improvements in the current crisis communication strategy and facilitate the performance evaluation of the crisis communication plan. 


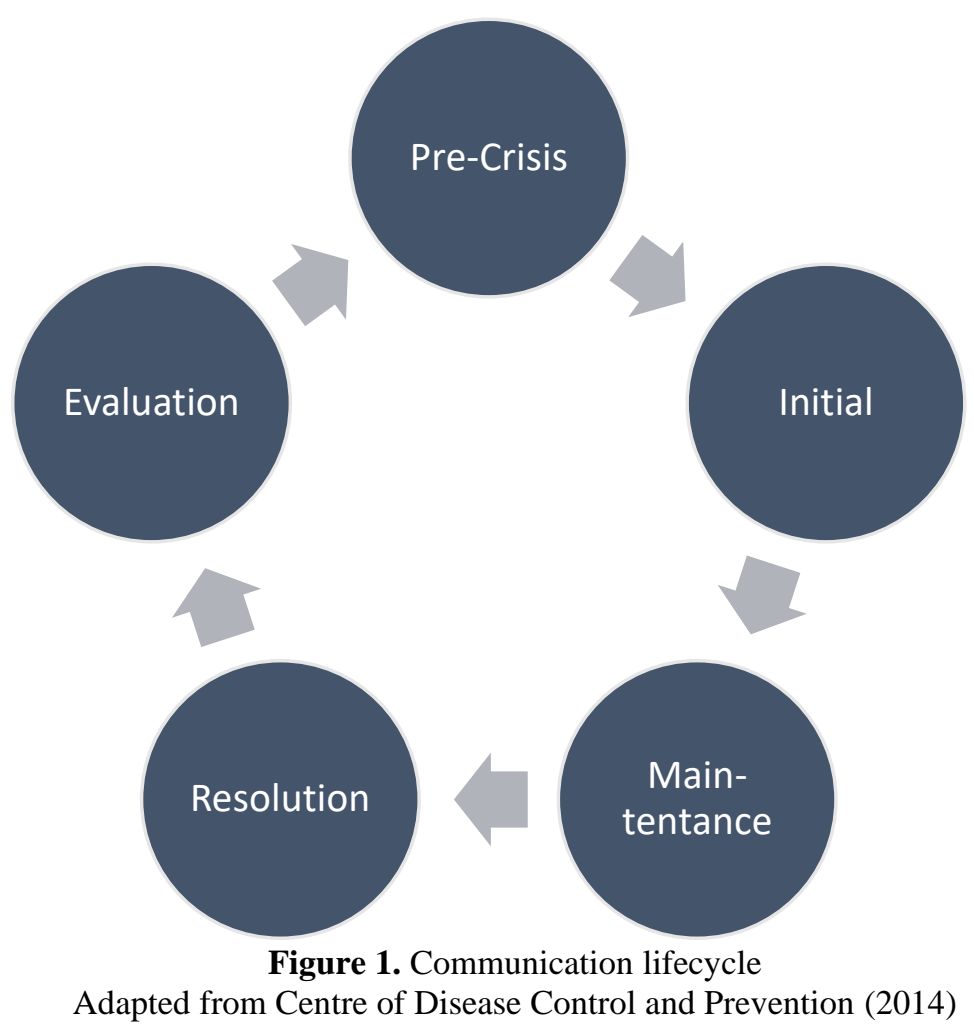

Speaking about the elements of successful communication, the CDC-publication has linked to the credibility of the information provided and the trust the recipient feels towards the source of information (Centre of Disease Control and Prevention, 2014). The sub elements of credibility are referring to accuracy of information and speed of release, while empathy and openness are associated with sub elements of trust. Accuracy of information is crucial, especially because of the unstable circumstances that prevail (Parmer et al., 2016). The general public will depend on the information handed to them and in order to provide reliable information, information management should ensure that information is factually correct; that communication uses simple, non-technical terms; that the information is repeated frequently and in different media contexts; and that all communication outlets share the same source (Centre of Disease Control and Prevention, 2014). Speed of information release is of equal importance in moments of crisis and can indicate that the source of the information has disaster handling plans in place (Centre of Disease Control and Prevention, 2014). However, it is important to notice that first information leave a lasting impression on the recipients - delivering wrong or conflicting narratives in times of crisis can affect the credibility of the information provider.

Empathy and caring should also be included in the message (Parmer et al., 2016), if appropriate, as this leads to better responsiveness towards the message from recipients. Similarly, it is important not to convey insincerity, or put on a show as this discredit the source (Centre of Disease Control and Prevention, 2014). On the other note, openness about the information available helps establishing trust among stakeholders. Trustworthiness is achieved by an honest and open attitude. Honesty entails that the realities of the situation are faced and responded to in a quick and appropriate manner. It should not lead to the premature release of information. For a flood disaster, as is the focus of this research, the CERC lifecycle with its embedded activities is applicable to the communication needs that arise from such an event. Similarly, the elements of successful communication identified can be used for improving communication in a disaster, where evacuations are necessary. In the scope of this study, the communication among victims in case of floods focuses primarily on the immediate response phase.

Relatively little research has been conducted to address specifically the communication needs during flood disasters, however, a past study has listed five common key characteristics of effective communication in the area of natural hazards risk and crisis communication (Steelman, \& McCaffrey, 2013). Engaging in interactive processes is the first key communication characteristic, enabling the dialogue and providing clarification of questions, tightly connected to the action of needs assessment (Burton, \& Ovadiya, 2014); the result can be better support for prevention and interventions (Steelman \& McCaffrey, 2013). Furthermore, local context has to be considered, the prevailing condition of the situation and environment from the point of view of those affected and involved, especially since "relating explanations of action to why they are needed and how they will make a difference given local conditions, can facilitate understanding and action" (Steelman \& McCaffrey, 2013). Another key characteristic they identified is the provision of information, which is timely, accurate, and useful, and done so in a reliable and honest manner. The messenger who conveys the message to the recipient is also of importance: their credibility in particular can affect how information is received and whether or 
not it is accepted. The final common characteristic of effective crisis communication is to establish working relationship by providing regular communication (Steelman \& McCaffrey, 2013; Nour et al., 2017).

\section{Concept of Humanitarian Logistics}

Humanitarian relief is the act of providing humanitarian aid in the face of a, most often, natural disaster, to the affected community. This is realised in the form of emergency supplies provision to those in need (Shafiai \& Khalid, 2016). Humanitarian logistics is therefore a mix of different kinds of operations that are involved in disaster relief and continuous support for developing regions. Generally, a distinction can thus be made between continuous aid work and disaster relief, which usually entails a limited time scope. Humanitarian logistics operations can be placed in the disaster management cycle between disaster preparedness and disaster response. Historically, logistics has always been a central element in humanitarian aid, seeing that efforts linked to transportation and other logistics services or operations make up a majority of activities involved in disaster relief (Kovács \& Spens, 2007). This concept was used by many scholars in developed and developing countries to study on disaster relief operation (Kovács \& Spens, 2007; Overstreet, et al., 2011).

\section{Success Factors of Humanitarian Logistics}

A previous study has extracted information from various publications and research articles to establish the critical factors that assist logistics processes related to the occurrence of natural disasters (Scarpin \& De Oliveira Silva, 2014). These success factors are related to the various parties involved in the humanitarian logistics processes, based on a model by Balcik et al. (2010). The humanitarian supply chain model in Figure 2 includes suppliers, donors, distribution centres and beneficiaries and takes into consideration both pre-disaster and post-disaster flows of supply (Scarpin \& De Oliveira Silva, 2014). In brief, the basic task of humanitarian logistics comprises acquiring and delivering requested supplies and services at the places and times they are needed. These supplies include items that are vital for survival such as food, water, temporary shelter and medicine among others.

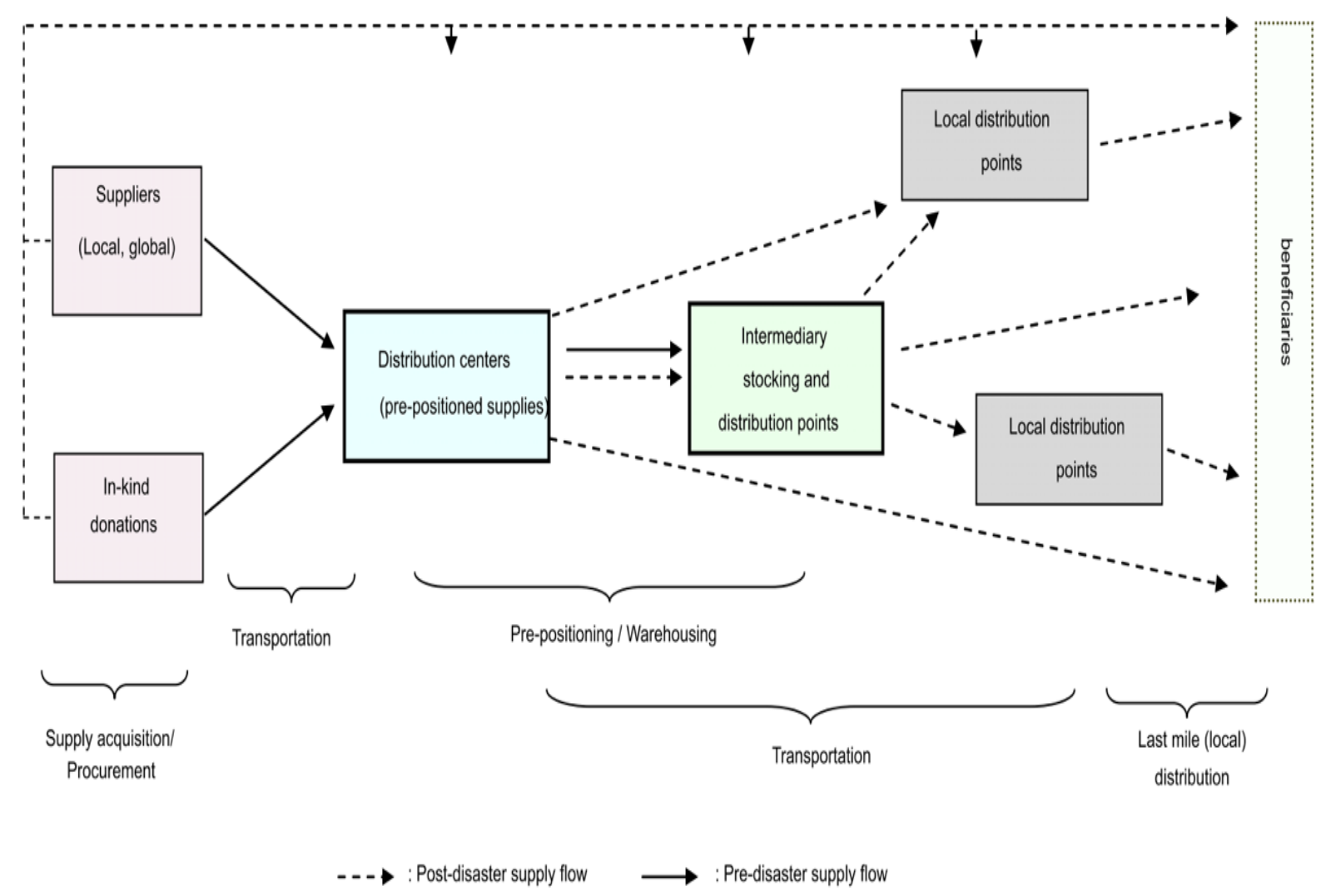

Figure 2. Humanitarian Supply Chain Model Source: Balcik et al. (2010)

In order to represent the individual needs of the parties involved, a differentiation is made between three different types of activities related to distribution centres such as resources, transportation and warehousing. The supply chain stakeholders and their respective success factors that were gathered from the literature (Scarpin \& De Oliveira Silva, 2014) and further confirmed with expert interviews are shown in Table 1. However, the category of beneficiaries was not considered, as the critical success factors found relate more to the activities of the other parties involved. As depicted in Table 1, the critical success factors demanded of suppliers include reliability in emergency situations, so that in a situation of crisis it can be guaranteed that the needs of the affected community are met. This factor is closely related to the aspect 
of relationship, as a network of trusted suppliers needs to be in place when disaster strikes. While donations can come from donors that are not close to the affected area, more crucial than location or proximity is the communication in terms of far reach of information and sufficient media coverage, as this helps generate large amounts of donations. Consideration means that donors bear in mind that donation contributions ought to help the affected citizens in the first place and should thus be in an acceptable condition.

Preparedness as critical success factor for resources refers to initial disaster kits with basic needs being made readily available prior to the first stages of a disaster event (Scarpin \& De Oliveira Silva, 2014). While emergency shelters are set up for the affected, the resources must be stored appropriately and ready for distribution to the shelters (Van Wassenhove \& Martinez, 2012). When it comes to transportation, nearly everyone who has the means and appropriate vehicles and time can aid with transportation, which is often realised by civilians during disasters (Scarpin \& De Oliveira Silva, 2014). To ensure safety, however, usually government bodies will be in control and oversee these activities. Important factors for warehousing of the donations and other supplies needed is a well-organised system of storing of goods and accurate information at all times. The location of a warehouse (centralised or decentralised) needs to be chosen based on the local context and needs (Scarpin \& De Oliveira Silva, 2014; Van Wassenhove \& Martinez, 2012).

Table 1. Success factors in Humanitarian Logistics

\begin{tabular}{ll}
\hline \multicolumn{1}{c}{ Stakeholder } & \multicolumn{1}{c}{ Critical Success Factors } \\
\hline Suppliers & Reliability and Relationship \\
\hline Donors & Communication and Consideration \\
\hline Distribution Centre - Resources & Preparedness \\
\hline Distribution Centre - Transportation & Agility and Safety \\
\hline Distribution Centre - Warehousing & Location, Organisation, and Information \\
\hline
\end{tabular}

Source: Adapted from Scarpin \& De Oliveira Silva (2014)

\section{METHODOLOGY}

To achieve the primary research objective, the current study run an analysis called a descriptive design to identify the communication effectiveness in disaster management through an online survey. Based on the data collected, a descriptive design can present the findings to provide an overall picture of the impression's participants had regarding current operations (Creswell, 2014). Additionally, this study applied a purposive sampling design which the participants were selected because they were being affected by the most recent floods in Kuantan, Pahang. The benefit of purposive sampling lies in the comparatively easy way in which generalisations can be made about the sample, since participants have undergone a pre-selection (Punch, 2005).

The information to be obtained from the participants was mostly centred on the aspects of logistics and distribution of aid in order to satisfy the second research objective. However, since the units of analysis were associated with different organisations and held very different positions, a semi-structured interview approach was chosen so that the areas of expertise of the participants could be highlighted during the interviews, while at the same time ensuring that the general flow of interview questions was followed. Target respondents were identified as individuals representing a government agency, a non-government organisation (NGO) or another organisation which is involved in flood management activities in Kuantan.

Target respondents were chosen by researching the government agencies identified in Directive No. 20 and NGOs actively involved in flood relief operations in the Kuantan area. The organisations were then approached using telephone in order to try and reach a person in charge that could provide information regarding flood management. Initial contact to the interview participants was usually either established via a phone call or WhatsApp messaging. Prior to the interview sessions, the respondents were informed about the approximate time frame needed to conduct the interview, which was about one hour. The interviews were then conducted in person, usually one-to-one, at the organisation the respondent represented. The questions for the interviews were divided into eight sections: flood events (Section A), process flow (Section B), information and communication (Section C), aid distribution (Section D), evacuation (Section E), flood handling (Section F), preparedness (Section G) and expertise (Section H). Each section consists of 1to 5 questions. Additionally, in formulating the questions, wording was chosen carefully so that the questions were open and not closed, to encourage lengthy answers by the participants.

\section{RESULTS AND DISCUSSION}

\section{Preliminary Study Results}

In a preliminary study conducted at the beginning of the research with the coordinator for the Universiti Malaysia Pahang (UMP) Alumni volunteers, information was gathered regarding the structure of organisations found locally that are involved in the humanitarian response following a flood. In accordance with the findings from the literature review, three stages of emergency response were identified namely pre-disaster, during disaster and post-disaster. The organisations of relevance are displayed in Table 2. 
Table 2. Results from preliminary study

\begin{tabular}{lll}
\hline Pre-Disaster & During Disaster & Post-Disaster \\
\hline National & Department of Welfare & Volunteers \\
\hline Firefighters & NGOs* & \\
\hline Police & i-Bantu & \\
\hline Soldiers & UMP & \\
\hline National Defence Department of Welfare & &
\end{tabular}

National Defence Department of Welfare

Note: $*$ NGOs $=$ Non-Government Organisation

The core activities at the pre-disaster phase mainly include preparations which is carried out in terms of humanitarian logistics and organisation. For instance, on the national level, starting 2016, one central government agency is entrusted with the coordinating activities leading the preparations and serves as central coordinator for other government agencies as well as organisations. The primary actions relate to the setting up and stocking of the flood shelters and the planning, organisation and actual carrying out of the transfer of flood victims during a flood event. During this preparation stage, as indicated during the preliminary meeting, those parties involved are firefighters, police, soldiers and national defence, as well as the Department of Social Welfare. While the latter is mainly concerned with organisational aspects of managing the shelter sites, the previous four forces are involved in transferring residents from high-risk areas before a flood event. The main participating parties during a flood occurrence particularly in Kuantan include the Department of Welfare, the NGO I-Bantu, higher education institutions, such as UMP and the NGO collective BBNGO, as stated by the respondent. The main involvement of the NGOs and higher education institutions is connected to sending goods of humanitarian aid relief once the flood has occurred and providing help in taking care of flood victims at the shelters.

In the post-disaster stage, the remaining activities centre on cleaning up the areas that were affected by the flood. This includes repairing and reconstruction of public means and infrastructure such as streets and buildings, works also need to be carried out at the shelters provided. As these are mostly public buildings such as schools or mosques and also city halls and assembly halls, efforts will have to be rut into restoring these locations to a state that they are ready to be used for their primary purposes again. With the Department of Social Welfare being in charge of the flood victim shelters, it is its responsibility to oversee their cleaning in the post-disaster phase. Only after the waters have completely retracted can the cleaning activities begin for the private properties of those citizens whose residential areas were affected by floods. These cleaning activities are carried out by volunteers. Although not specified during the preliminary meeting, these volunteers are sent from a wide range of organisations and institutions, such as higher education institutions, schools or NGOs. They will usually also provide initial care kits containing essential foodstuffs and staple foods such as rice, noodles and sugar.

\section{Results for R0 1: To Identify the Effectiveness of the Communication Mechanism among Flood Victims}

In relations to flood events (Section A), 39 percent of participants have described their experience and emotional state as normal or accepting and calm. This may be due to flood familiarity. Additionally Figure 3 shows that the participants were followed by anxious and worrisome ( 22 percent), followed by normal shocked (32 percent), or happy ( 7 percent).

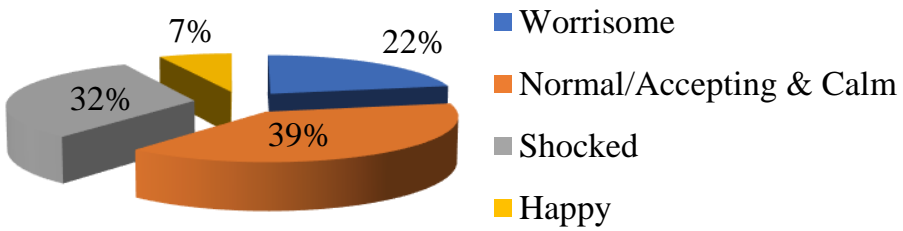

Figure 3. Experience and emotional state

With regards to source of information, most of the participants mentioned that they received the information about the flood through WhatsApp (82 percent). The second most selected answer was television (29 percent), followed by Facebook (21 percent), radio (14 percent), SMS and personal interaction with neighbours and/or friends (both represent 8 percent). On another note, 2 percent of participants stated that they received the fact about the flood via Twitter and also another 2 percent of participant was only made aware of the flood through observation of rising water levels in front of their house, as exposed in Figure 4. 


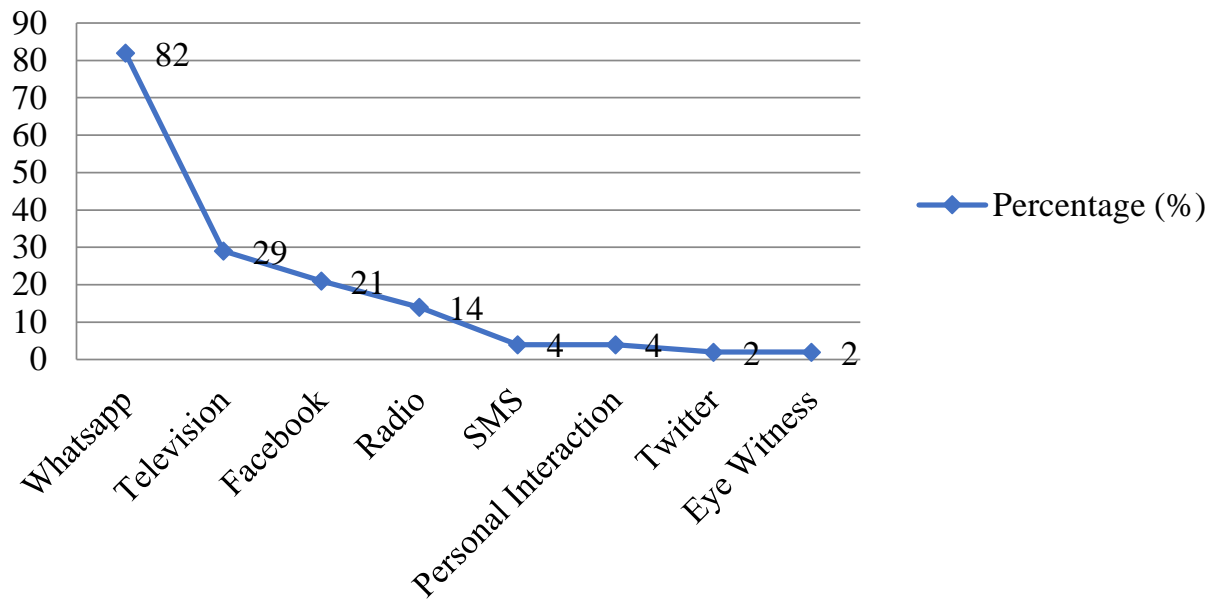

Figure 4. Source of information

Table 3 summarizes the suggestions on how to improve the communication between flood victims, NGOs and the government. 13 percent of respondents have asked for more regular communication either via phone, WhatsApp or SMS and for more honest, clearer and accurate information, respectively. Moreover, 11 percent participants suggested that they would like to have meetings in the flood affected area between victims and agencies and parties involved. The remaining suggestions were reported at 3 percent each such as the request for an official flood website, information flow through Rukun Tetangga (Malaysian neighbourhood watch), information flow via Jawatankuasa Kemajuan dan Keselamatan Kampung $(J K K K)$, facilitate more volunteers and equipment during the flood, better coordination, increasing awareness and more comfortable relief centres. The suggestions are vital to be implemented in the near future so that the communication between flood victims, NGOs and the government can be improved.

Table 3. Suggestions to improve communication between flood victims, NGOs and government.

\begin{tabular}{lc}
\hline Suggested Improvements & Percentage (\%) \\
\hline Regular communication & 13 \\
\hline Honest, clear, accurate information & 13 \\
\hline In person meetings & 11 \\
\hline Official flood website & 3 \\
\hline Information via neighbourhood watch (Rukun tetangga) & 3 \\
\hline Information via JKKK & 3 \\
\hline More volunteers and equipment & 3 \\
\hline Better coordination & 3 \\
\hline Increasing awareness & 3 \\
\hline Comfortable relief centres & 3 \\
\hline
\end{tabular}

Aid supplies received by participants include food and beverages, bedding, transportation, toiletries, money and medication. From 28 respondents, only 22 had received aid in any one of the forms mentioned above. Figure 5 reveals that 14 percent of these respondents mentioned that the aid supplies were not sufficient to fulfil their needs, 18 percent were unsure whether this was the case and the rest ( 68 percent) felt that the supplies met their needs and were sufficient. The goods were supplied by Social Welfare Department/Jabatan Kebajikan Masyarakat (31 percent), the government (15 percent), an NGO (15 percent), Rukun Tetangga, a political party, SRS or Skim Rondaan Sukarela, villagers and JKKK (all 7 percent). When asked how aid supplies are given to the community of the participants, 33 percent identified the emergency shelters, another 18 percent claimed that they did not receive aid at all and 7 percent were unsure. Another 7 percent said that the village chief distributed the aid, while 7 percent more stated that aid was received in the village and another 7.4 percent said that aid reached their community through land aid. Other sources of aid identified include NGOs, political parties, patrols, volunteers, representatives and JKKK (all 4 percent).

On the other hand, as displayed in Figure 6, 76 percent of participants felt that the relocation of flood victims was handled right on time. 14 percent disagree with this and 10 percent of the respondents were not sure about this. 67 percent had the impression that the relocation of victims was smooth and orderly. While 10 percent remain unsure about this, 23 percent of respondents disagree and were not satisfied with the proceeding. Finally, regarding the efficiency of relocation activities, 67 percent felt that these were efficiently handled. 14 percent remain unsure about the efficiency and 19 percent felt that the process was not handled efficiently. 


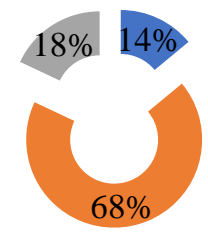

Insufficient $\square$ Sufficient $\square$ Unsure

Figure 5. Received aid supplies

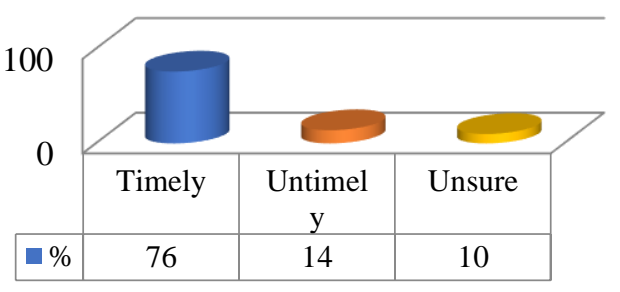

Figure 6. Timeliness of relocation

Apart from that, the respondents were asked to list the agencies or organisations that are usually active participating in disaster management activities of their residential area. Most participants (28 percent) identified the fire department, police department and Angkatan Tentera Malaysia (ATM), followed by Jabatan Sukarelawan Malaysia (RELA) with 19 percent, JKM or Jabatan Kebajikan Masyarakat (14 percent), MPK or Majlis Perbandaran Kuantan (11 percent). NGOs, local residents and local schools were each named by 6 percent. APM or Malaysia Civil Defence Department, Skim Rondaan Sukarela (SRS), volunteers and JKKK were each named by 3 percent of respondents. Another 3 percent stated that they knew no agency, as exposed in Table 4. Importantly, 68 percent of the respondents felt satisfied or highly satisfied with the government's actions in the process of flood disaster management. 14 percent remained undecided and 18 percent expressed that they were not satisfied with the processes of the government's flood management.

Table 4. Organizations active in local disaster relief

\begin{tabular}{lc}
\hline Organizations Active in Local Disaster Relief & Percentage (\%) \\
\hline Police, Fire Department & 28 \\
\hline Jabatan Kebajikan Masyarakat & 14 \\
\hline NGOs & 6 \\
\hline Schools & 6 \\
\hline SRS & 4 \\
\hline JKKK & 4 \\
\hline RELA & 19 \\
\hline MPK & 11 \\
\hline Local residents & 6 \\
\hline Volunteers & 3 \\
\hline None & 3 \\
\hline
\end{tabular}

In relations to the improvements, if any, they had experienced over the recent years, 14 percent of the participants commented on the more systematic nature of flood management. 18 percent of them responded that they were not sure whether improvements had taken place or not. 25 percent had the impression that the handling was unchanged and had remained the same over the past years, while 11 percent expressed that they felt general improvement overall. Furthermore, 7 percent of participants claimed that shelters and aid distribution was better now. On top of that, 4 percent stated that drainage and river management had improved and another 4 percent found that help was employed in a faster way, as depicted in Table 5.

Table 5. Areas of improvement

\begin{tabular}{lc}
\hline Areas of Improvement & Percentage (\%) \\
\hline More systematic & 14 \\
\hline Better drainage/river management & 4 \\
\hline General improvement & 11 \\
\hline Unsure & 18 \\
\hline Better shelters and aid & 7 \\
\hline Faster help & 4 \\
\hline No improvement & 25 \\
\hline
\end{tabular}

Asked, whether the respondents had the feeling that their residential area was well-prepared in a complete manner for future flood incidents, 61 percent of them agreed. 18 percent were unsure about the issue and 21 percent felt that their communities were in fact not entirely prepared for upcoming floods in the future, as shown in Figure 7. 


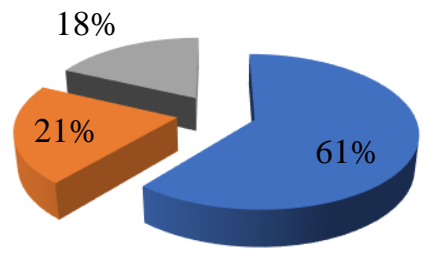

Well-prepared $\quad$ Not prepared $\quad$ Unsure

Figure 7. Local preparedness for future floods

In relations to steps to take which participants were notified about before and during the flood, 22 percent named being careful or taking care of themselves as one. Related to this, 18 percent stated they were told to stay alert on updates and developments and 11 percent said they were informed to pack or be ready to move. 6 percent remembered they were told to keep off electrical goods and to save their valuables respectively. Steps identified by 3 percent of participants include keeping enough food supplies, providing assistance to others who are in need, instructions to move, remaining in the safe area during floods, saving family first, moving things in the house to a higher level, going to the emergency shelters, and following instructions from authorities and the government, as illustrated in Table 6.

Table 6. Steps for flood preparation and event

\begin{tabular}{lc}
\hline Steps for Flood Preparation and Event & Percentage (\%) \\
\hline Being careful/taking care of themselves & 22 \\
\hline Being ready for evacuation & 11 \\
\hline Safekeeping of valuables & 6 \\
\hline Providing assistance & 3 \\
\hline Remaining in safe areas & 3 \\
\hline Moving things to upper level & 3 \\
\hline Following authorities' instructions & 3 \\
\hline Staying alert & 18 \\
\hline Switching off electrical goods & 6 \\
\hline Keeping off sufficient food supplies & 3 \\
\hline Keeping of moving instructions & 3 \\
\hline Saving family first & 3 \\
\hline Seeking emergency shelters & 3 \\
\hline
\end{tabular}

\section{Results For RO 2: To Recognise the Critical Success Factors in Managing Humanitarian Logistics in the Case of Flood Events}

The next findings are related to the critical success factors in managing humanitarian logistics in the case of flood events. As shown in Table 7, there were 17 categories captured in the interviews and were used as codes for the content analysis. The top five most common codes from the transcribed interviews include communication (91), shelters (52), supplies (41), coordination (40), and transportation (34). The bottom five was related to awareness (7), manpower (6), technology (5), warning (5) and expenses (2). None of the codes were identified in all interactions.

Table 7. Occurrence of codes per interview

\begin{tabular}{|c|c|c|c|c|c|c|c|c|c|}
\hline Section & Code & 1 & 2 & 3 & 4 & 5 & 6 & 7 & Total \\
\hline A & Coordination & 14 & 9 & 10 & - & 5 & - & 2 & 40 \\
\hline B & Transportation & 6 & 12 & 13 & - & 1 & 2 & - & 34 \\
\hline $\mathrm{C}$ & Expenses & 1 & - & - & - & - & - & 1 & 2 \\
\hline D & Warning & 5 & - & - & - & - & - & - & 5 \\
\hline $\mathbf{E}$ & Communication & 7 & 26 & 24 & 5 & 14 & - & 15 & 91 \\
\hline $\mathbf{F}$ & Shelter & 4 & 6 & 12 & 15 & 4 & 7 & 4 & 52 \\
\hline $\mathbf{G}$ & Rescue & 5 & - & 3 & - & 2 & 1 & 2 & 13 \\
\hline $\mathrm{H}$ & Delays & 5 & 1 & - & - & 1 & - & 1 & 8 \\
\hline $\mathrm{I}$ & Post-Disaster & 5 & 3 & - & - & 1 & 2 & 1 & 12 \\
\hline $\mathbf{J}$ & Preparedness & 1 & 2 & 1 & 4 & 1 & 2 & - & 11 \\
\hline $\mathrm{K}$ & Awareness & 1 & 2 & - & 2 & 2 & - & - & 7 \\
\hline$L$ & Improvements & 1 & 5 & 1 & 2 & 2 & - & 2 & 13 \\
\hline M & Mindset & 1 & 3 & 3 & 6 & 1 & - & 4 & 18 \\
\hline $\mathbf{N}$ & Supplies & - & 26 & 2 & 3 & 6 & 2 & 2 & 41 \\
\hline 0 & Technology & - & 1 & - & - & 4 & - & - & 5 \\
\hline$P$ & Manpower & - & - & 2 & 1 & 3 & - & - & 6 \\
\hline $\mathbf{Q}$ & Knowledge & - & - & 1 & 1 & 7 & 1 & 3 & 13 \\
\hline
\end{tabular}




\section{Discussion on the Effectiveness of the Communication Mechanism among Flood Victims}

It is interesting to see the development of the communication channels in recent years. From this study, the majority of participants expressed that they received information about the flood incidents and updates about its development via WhatsApp Messenger. This indicates that official channels of communication authorised by local authorities or the government, such as broadcasts on the radio or television are not the primary source of information for residents anymore, even, or perhaps especially, in emergency situations. Messenger apps convey the most information to residents, even though it should be kept in mind that television as source of information came in second behind WhatsApp and before Facebook. Moreover, 13 percent of participants also use the radio as source for updates also indicate that it still is a relevant medium. While a few participants refrained from suggesting improvements for the communication across the stakeholders related to a disaster event, many respondents do have ideas on how to make the interaction better. The desire for more regular communication implies that currently, information is handed out in irregular intervals, or at least appears this way to the affected flood victims. It is important to notice that the channel of communication related to this suggestion is always tied to a mobile device (phone, WhatsApp or SMS). This strongly correlates with the findings of (Reynolds \& Shenhar, 2009), that crisis communication has to be clear to avoid mixed messages, but also controlled and fast.

Especially during times of crisis, mobile devices provide access to information instantaneously, so the responsible agencies should pursue to present accurate updates to the public and to be the first to give out information. Furthermore, participants expressed that they wished for more honest, clearer and accurate information. In these cases, the source of the information needs to be investigated further, however. Whether the inaccurate, unclear information originated from official sources remains unclear. Nevertheless, the expressed wish for clearer communication is an indicator for the still unsorted communication field that has yet to receive clean-cut instructions and a direction. One participant called for an official website for information on the flood updates as a central place of refuge, so to speak. This either means that the respondent is unaware of the existence of such a site, or that the information provided are not of use to them, are not updated fast enough, or are in some other way faulty or unreliable.

The effectiveness of the underlying disaster communication mechanisms in place is therefore questionable. An aspect that stands out in the results of the survey regarding disaster communication is that in a range of suggestions, participants sought after personal connection and interaction for their suggestions, when clustering together those who wish to meet in person with responsible agencies in the affected area, and those who wish for information to reach them via Rukun Tetangga, or JKKK. In advancing the communication mechanisms, the factor of personal interaction should be considered, perhaps realising such meetings, so that especially in disaster or emergency contexts the residents and flood victims feel safe and taken care of. As pointed out in the literature review, empathy as well as honesty are considered important factors in disaster communication (Centre of Disease Control and Prevention, 2014); taking the time to meet residents would show them a sincere interest in their lives and situation.

As a result, the public feel respected and heard and can then in turn listen to instructions and new information. The express wishes from the participants reflects Parmer et al. (2018) statement that an audience can take away from such an interaction, whether or not the speaker can truly understand what they are going through; in a sense this will give the public a chance to know for certain. Personal interaction can also be achieved by meeting another suggestion, which is the raising of awareness. Even though the resources may exist for residents, if nobody is aware of them, they remain useless, as it perhaps holds true for the info banjir website - as stated before, either it is not updated as it should be, or perhaps residents in affected areas have not been made aware of its existence yet. Similarly, flood preparedness information and risk awareness should be communicated and even promoted in affected areas. This way, information can be shared in communities more easily and official channels can make sure that truthful and honest information is passed on to the people.

Furthermore, when asked about the steps the respondents should act as residents in a flood-prone area, most answers were given that reflect the content of the guidelines issued by DID for flood preparedness of the community. It is worth noticing that many of these measures were named only once by participants in the survey. This indicates on one hand that the guiding principles of DID flood preparedness are accessible in some way to residents in flood affected areas, as they still remembered some aspects of flood preparedness, disregarding where it originated from. Communication between authorities, agencies, NGOs and flood victims is still in need of improvements, as the suggestions made by participants of the study suggests, both in regard to emergency updates as well as to heightening community awareness on the right actions to take in preparation of upcoming floods. The lack of the public's satisfaction with current disaster communication reflects the need to create platforms and dialogue to increase its effectiveness in the face of flood events.

\section{Discussion on The Critical Success Factors in Managing Humanatarian Logistics in the Case of Flood Events}

The respondents participating in the interview commonly agreed that overall, disaster management has improved in Malaysia in the years following the 2014 flood. One participant concern was expressed particularly on vehicles. Four of the respondents commented on the lack of vehicles that are available to their organisation or in general, for executing rescue activities. Due to flood incident which makes evacuation necessary, participant from interview 1 pointed out that " $4 x 4$ vehicles, big lorries are necessary to enter flooded areas, but [are] not available to NGOs". Many government agencies, respondent 1 remarks, do not possess their own 4x4 or 6x6 transportation. In the case of the welfare department this means dependency on rental vehicles, other organisations, or private volunteers who lend their vehicles to the agency. 
In the past, this has resulted in the department not being able to meet delivery schedules, since several shelters need to be serviced by them. Delays in receiving supplies at the shelters are the result. Through the course of the interviews, the information provided by the respondents has been similar and not contradictory regarding the agencies involved in the processes of flood management and in the responsibilities held by each institution and organisation. In terms of improvements from the past years, the term coordination has been brought up with relative frequency. All respondents that were met, reported that the establishment of the organisation National Disaster Management Agency (NADMA) last year has contributed to an improvement of coordination matters. As respondent 2 shared during the interview, previously, aid organisations worked by themselves in general and served their own assigned areas in times of need.

As this provision of aid was not controlled centrally, however, representatives of more than one aid organisation would turn up at the same place and at more or less the same time, leading to chaos and confusion of both the volunteering staff as well as the flood victims in need. With NADMA, these unnecessary hurdles are overcome, and resources can be maximised, as respondent 1 pointed out. Respondent 2 is happy about this development, since now there are "meetings and exchange of ideas for the next floods with NGOs that have all different specialisations, all different knowledge in flood". Communication now takes place centrally, via WhatsApp and organisations can post their need for e.g. a $4 \times 4$ to pick up donations in the group and the network of people responding to this request is now bigger due to the central connectedness of the government agencies and NGOs under the control of NADMA.

Looking at the codes identified in the interview transcripts and the information offered during these interviews, critical success factors relating to humanitarian logistics can be established. The two central aspects the interviews initially aimed to investigate in detail were evacuation activities and transport of aid supplies. However, the participants of the study who responded to the interview request were only remotely connected to these activities. While evacuation and distribution of aid supplies was still relevant and pursued as topic during the interviews, other areas were sometimes discussed at greater length, so as to gain a better understanding of the topic of disaster and flood management in general. Very closely related to one another are the first two success factors, communication and coordination. Especially, due to the time constraint related to humanitarian relief operations, proper coordination of resources forms the core of good humanitarian logistics.

However, without communication even the most elaborate coordination plan will not be successful and therefor also needs to be a priority in managing and structuring the disaster management activities. Knowledge comprises not only having experts on critical topics on board, but also to implement this knowledge in an effective manner, as respondent 5 pointed out: Application of knowledge thus also belongs to the success factors of relief operations. Preparedness of the agencies and also individuals working on the scene is the last crucial factor in humanitarian relief operations. As with the unpredictable aspect of their nature, disasters can occur without warning and without prior planning for it. To safeguard communities, unambiguous and clear SOPs need to be in place at the integrated agencies and they need to be understood and known by the individuals who execute them.

\section{CONCLUSION AND IMPLICATIONS}

As the conclusion, this study has able to highlight and identify the critical success factors for humanitarian response in the case of flood management in Kuantan. The core factors can be divided into four such as coordination, communication, knowledge, and preparedness. Most have noticed that many parties like government agencies, NGOs and other stakeholders are involved in the disaster management activities in Malaysia, therefore it is predicted that the coordination of communication in such an environment is the more crucial. When dealing with any disaster incident, a proper communication (clear, reliable, fast and accurate information) will provide support and gives its voice to coordination. Other than that, knowledge comprises not only having experts on critical topics on board, but also to implement this knowledge in an effective manner. Preparedness of the agencies and also individuals working on the scene is the last crucial factor in humanitarian relief operations. As with the unpredictable aspect of their nature, disasters can occur without warning and without prior planning for it. To safeguard communities, unambiguous and clear standard operating procedures need to be in place at the integrated agencies and they need to be understood and known by the individuals who execute them.

To further develop NADMA, which was established as coordinating control for disaster management only in 2016, an expansion of the staff seems a feasible idea. By establishing local NADMA officers and permanent staff, communication on the ground is simplified. A dialogue is then possible, where lessons learnt can be reflected on a common ground and feedback can be expressed from both sides regarding what went well and what did not during the latest disaster incident. Furthermore, three specialised teams could be integrated into the team of NADMA in the future; one focussing on the technical and technological advancement of drainage and irrigation development; another comprising expert in the field of disaster management; and a third team that is focussed around community outreach.

\section{ACKNOWLEDGEMENT}

We are thankful to everyone who were willing to involve in this study by participating in the survey and to all participants who agreed to be interviewed.

\section{FUNDING}

This work is supported by the Ministry of Higher Education, under the Fundamental Research Grant Scheme (FRGS) of RDU150107. 


\section{REFERENCES}

Balcik, B., Beamon, B. M., Krejci, C. C., Muramatsu, K. M., \& Ramirez, M. (2010). Coordination in humanitarian relief chains: Practices, challenges and opportunities. International Journal of Production Economics, 126(1), 22-34. Doi:10.1016/j.ijpe.2009.09.008

Burton, C., \& Ovadiya, M. (2014). Communication following a disaster. Social Protection and Labor Systems -World Bank Group.

Chan, N. W. (1997). Increasing flood risk in Malaysia: causes and solutions. Disaster Prevention and Management: An International Journal, 6(2), 72-86. Doi:10.1108/09653569710164035

Chan, N. W. (2012). Impacts of disasters and disasters risk management in Malaysia: the case of floods. Economic and Welfare Impacts of Disasters in East Asia and Policy Responses., (December), 503-551. Doi:10.1007/978-4-431-55022-8

Centre of Disease Control and Prevention (2014). Crisis + emergency risk communication. U.S. Department of Health and Human Services. Retrieved 14 July 2018, from http://emergency.cdc.gov/cerc/resources/pdf/cerc_2014edition.pdf

Creswell, J. W. (2014). Research Design: Qualitative, Quantitative, and Mixed Methods Approaches. SAGE Publications. Doi:10.1007/s13398-014-0173-7.2

Department of Irrigation and Drainage, Ministry of Environment and Water (2020). Fenomena banjir di Malaysia. Retrieved May 28, 2020, from https://www.water.gov.my/jps/resources/auto\%20download\%20images/5847aab46bb32.pdf

Emergency Events Database (EM-DAT). The international disasters database, 2017. Retrieved May 28, 2020, from https://www.emdat.be/

Gupta, S. K. (2010). Urban Hydrology. Modern Hydrology and Sustainable Water Development, $297-321$. Doi:10.1002/9781444323962.ch10

Jamaludin, M. H., S. Jaafar, B. K. C., \& Abdullah, Z. (2013). FLOOD : Kuantan town centre almost paralysed, 37,100 evacuated in 4 states. New Straits Times. Retrieved June 30, 2018, from http://www2.nst.com.my/latest/font-color-red- flood-font-kuantantown-centre-almost-paralysed- 37-100-evacuated-in-4-states-1.421108

Khalid, M. S. Bin, \& Shafiai, S. B. (2015). Flood disaster management in Malaysia: an evaluation of the effectiveness flood delivery system. International Journal of Social Science and Humanity, 5(4), 398-402. Doi:10.7763/IJSSH.2015.V5.488

Kovács, G., \& Spens, K. M. (2007). Humanitarian logistics in disaster relief operations. International Journal of Physical Distribution \& Logistics Management, 37(2), 99-114. Doi:10.1108/09600030710734820.

Malay Mail Online. (2018). Number of flood evacuees near 12,000 in Johor, Terengganu, Pahang, Sabah. The Malay Mail Online.

Malay Mail. (2013). Heavy rain continues, over 38,000 flood victims throng relief centres in Pahang. Retrieved May 27, 2018, from https://www.malaymail.com/s/577089/heavy-rain-continues-over-38k-flood-victims-throng-relief-centres-in-pahang

Manuel, J. (2014). Crisis and emergency risk communication: lessons from the Elk River spill. Environmental Health Perspectives. Doi:10.1289/ehp.122-A214

Nour, M., Alhajri, M., Farag, E. A. B. A., Al-Romaihi, H. E., Al-Thani, M., Al-Marri, S., \& Savoia, E. (2017). How do the first days count? A case study of qatar experience in emergency risk communication during the MERS-CoV outbreak. International Journal of Environmental Research and Public Health, 14(12). Doi:10.3390/ijerph14121597

Overstreet, R.E., Hall, D., Hanna, J.B., \& Kelly Rainer, R. (2011). Research in humanatarian logisctics. Journal of Humanataraian Logicstics and Supply Chain Management, 1(2), 114-131.

Parmer, J., Baur, C., Eroglu, D., Lubell, K., Prue, C., Reynolds, B., \& Weaver, J. (2016). Crisis and emergency risk messaging in mass media news stories: is the public getting the information they need to protect their health?. Health Communication, 31(10), 1215-1222. Doi:10.1080/10410236.2015.1049728

Punch, K. (2005). Introduction to Social Research - Quantitative \& Qualitative Approaches. Sage, (c), 320. Retrieved 28 May 2018, from http://www.qualitative-research.net/index.php/fqs/article/view/109/227

Reynolds, B. J., \& Shenhar, G. (2009). Crisis and emergency risk communication. In Koenig and schultz's Disaster Medicine: Comprehensive Principles and Practices (pp. 326-344). Doi:10.1017/CBO9780511902482.024.

Scarpin, M. R. S., \& De Oliveira Silva, R. (2014). Humanitarian logistics: empirical evidences from a natural disaster. Procedia Engineering, 78, 102-111. Doi:10.1016/j.proeng.2014.07.045

Shafiai, S., \& Khalid, M. S. (2016). Examining of issues on flood disaster management in Malaysia. International Review of Management and Marketing, 6(S7), 51-56.

Shakir, A., Saudi, M., Juahir, H., Azid, A., Khairul, M., Kamarudin, A., ... Samsudin, M. S. (2015). Flood risk pattern recognition using chemometric technique: a case study in Kuantan River Basin. Jurnal Teknologi, 1(August 2016), 137-141. Doi:10.11113/jt.v74.3772

Saifulsyahira, J., Edre, M. A., Ahmad Farhan, A. F., \& Muhamad Hanafiah, J. (2016). Governance of flood disaster management: Malaysia case study. International Journal of Public Health and Clinical Sciences, 3(1), 17-30.

Shafiai, S. (2016). Flood disaster management in Malaysia: a review of issues of flood disaster relief during and post-disaster, (1983), 163-170. Doi:10.15405/epsbs.2016.08.24

Steelman, T. A., \& McCaffrey, S. (2013). Best practices in risk and crisis communication: implications for natural hazards management. Natural Hazards, 65(1), 683-705. Doi:10.1007/s11069-012-0386-z

Van Wassenhove, L. N., \& Pedraza Martinez, A. J. (2012). Using OR to adapt supply chain management best practices to humanitarian logistics. International Transactions in Operational Research, 19(1-2), 307-322. Doi:10.1111/j.1475-3995.2011.00792. 
Zakaria, S. F., Zin, R. M., Mohamad, I., Balubaid, S., Mydin, S. H., \& Mdr, E. M. R. (2017). The development of flood map in Malaysia. AIP Conference Proceedings (pp. 1903). Doi:10.1063/1.5011632

Zaidi, S. M., Akbari, A., \& Ishak, W. M. F. (2014). A critical review of floods history in Kuantan River Basin: challenges and potential solutions. International Journal of Civil Engineering \& Geo-Environment, 5.

\section{AUTHORS' BIOGRAPHY}

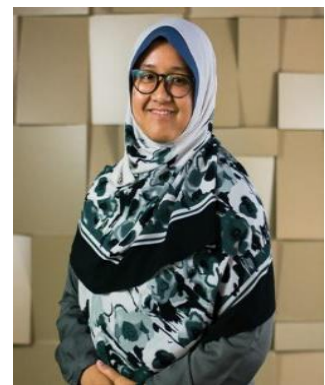

Puteri Fadzline bt Muhamad Tamyez is currently the Deputy Dean of Research and Postgraduate Studies in Faculty of Industrial Management, Universiti Malaysia Pahang. She graduated from Universiti Technology MARA, Shah Alam, with a PhD in Business Management and from Universiti Sains Malaysia, Penang with BSc and MSc degrees in Bioresources, Paper and Coating Technology under the School of Industrial Technology. Prior to Universiti Malaysia Pahang, she had accumulated industrial experiences in the furniture and wood flooring industry for 4 years. At both companies, she is responsible for matters related to Quality Control and Production processes. Her research interests are Business Management, Innovation Management, Product Management, and Research Methodology. She can be contacted at Faculty of Industrial Management, Universiti Malaysia Pahang, Lebuhraya Tun Abdul Razak, 25300, Kuantan, Pahang, via email at fadzline@ump.edu.my or phone at +09-5492445.

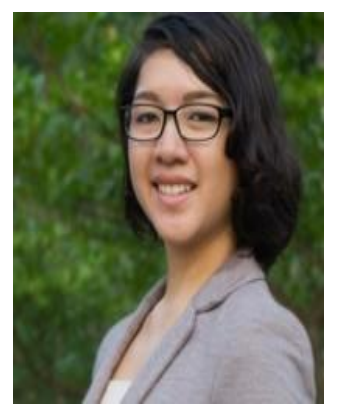

Natalie Christiane Isabella Gerth is a former Business Engineering student at ESB Business School, Reutlingen University.

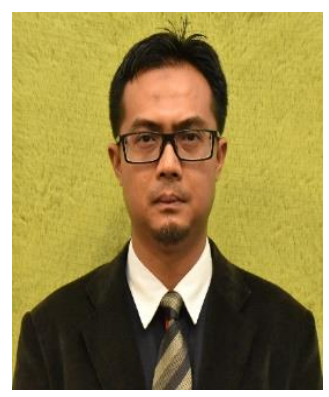

Abdul Rahman Zahari is a Senior Lecturer in the College of Business Management and Accounting, Universiti Tenaga Nasional, Malaysia and has received his Ph.D. in Entrepreneurship from the Universiti Malaysia Pahang. He has more than 20 years of experience teaching courses in integrated marketing communications, digital marketing, sales management, international business, operations management, marketing/entrepreneurship research, and entrepreneurship. His research interests are in brand equity, corporate social responsibility, corporate governance, renewable energy, student publishing companies, and smart meters. He has published his research in the International Journal of Energy Sector Management, WSP Publishing, IGI Global Publication, Contemporary Marketing Review, International Journal of Business Management, Journal of Entrepreneurship Education, and The Journal of Asian Finance, Economics and Business. He also holds a trainer certificate from the Human Resources Corporation Berhad and is involved in various consulting projects with Tenaga Nasional Berhad and Pelitawanis. 


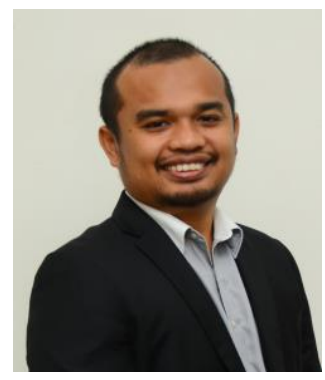

Mohd Nizam bin Abdul Rashid is currently the General Manager of UMP Technology Pvt. Ltd. (UMPT), a wholly owned subsidiary of UMP Holdings Pvt. Ltd. He graduated from Universiti Malaya with MSc. and BSc. Degree in Biotechnology. Prior joining UMPT, he was a Senior Assistant Registrar in Technology Transfer Office of Universiti Malaysia Pahang (UMP) and was an Associate in Malaysian Technology Development Corporation (MTDC). He has 13 years of accumulated experience in technology development and commercialisation. His research interest are in Commercialisation Management, Business Management and Innovation Strategy. He can be contacted at UMP Technology Pvt. Ltd., Lebuhraya Tun Abdul Razak, 25300, Kuantan, Pahang, via email at nizam@umpholdings.my or phone at $+013-3427627$. 